\title{
Effects of aeration and mineral supply on growth and mineral content of shoots and roots of apple trees (var. 'Golden Delicious' on M IX)
}

\author{
J. Visser ${ }^{1}$, J. Th. Locher ${ }^{2}$ and R. Brouwer ${ }^{3}$ \\ 1 Ysselmeer Polders Development and Settlement Authority, Kampen, the Netherlands \\ 2 Institute for Biological and Chemical Research of Field crops and Herbage, \\ Wageningen, the Netherlands \\ 3 Laboratory for Plant Physiological Research, Agricultural University, Wageningen, \\ the Netherlands
}

Received: 7 April 1971

\section{Summary}

Young (1- or 2-year-old) 'Golden Delicious' apple trees on rootstock M IX were grown in containers with clay or with nutrient solution. The oxygen supply was varied by inundating the clay soil to various heights and by bubbling air through the solution or not.

Shoot elongation was followed by regular measurements of the length of a number of shoots. In addition plants were harvested at regular time intervals. At each harvest dry weights of various parts of the plants and macronutrient and soluble carbohydrate content were determined. With differences between the individual ions in general mineral content decreased at unfavourable aeration conditions whereas the soluble sugar content increased.

\section{Introduction}

In modern horticultural practice the use of slowly growing root stocks led to an enlarged susceptibility to unfavourable soil conditions (Butyn, 1961; van der Kloes, 1965). Segeren and Visser (1969) found that among the macronutrients only the calcium content in leaves and fruits decreased in badly aerated soils. Since the calcium balance appeared to be strongly correlated with the incidence of 'bitter pit' continued research under controlled conditions was wanted. In addition the variety 'Cox's O.P.' on M IX showed specific growth disorders, the so-called 'Cox disease' (Visser, 1968), which due to the rather variable results made a more accurate control of both root and shoot environment highly desirable.

This paper will deal with experiments in soil and water culture in which at first the effects of variations in the oxygen supply were studied.

\section{Methods}

A. The experiments started in 1968 when 1-year-old 'Golden Delicious' apple trees on rootstock M IX were grown in 60-litre metal cylinders filled with loam soil $(27 \%$ clay 
and $3 \%$ organic matter). Growth started in April and at the end of July each tree had 4 or 5 growing shoots with an average length of about $20 \mathrm{~cm}$. Roots were distributed throughout the whole container. At 25 July 60 containers were inundated to a level of $5 \mathrm{~cm}$ below surface, whereas an equal number was normally drained. In the inundated series inundation was maintained for 3 days, 1, 2, 4 or 6 weeks.

B. In 1969 this experiment was repeated with 2-year-old trees, whereas additionally the effect of inundation to $30 \mathrm{~cm}$ below surface was studied. Besides in a small group of plants periods of inundation ( 0 to 7 days a week) to 0 or $30 \mathrm{~cm}$ below surface alternated with periods of free drainage ( 7 to 0 days a week).

C. Comparable 2-year-old trees were grown in 1969 on Hoagland nutrient solution in a glass house. The temperature of the solution was maintained at $16^{\circ} \pm 1^{\circ} \mathrm{C}$ whereas the air temperature varied with weather conditions. Large ventilators which switched on automatically when glasshouse temperature exceeded $20^{\circ} \mathrm{C}$ could not prevent glass house temperatures to become $5^{\circ}$ to $7^{\circ}$ higher than outdoors during clear days. At the start the root systems were rinsed and cut down to a number of 5-7 branches of 15 to $20 \mathrm{~cm}$ the ends of which touched the nutrient solution so that the new roots could penetrate into the solution (Mori, 1966). During the first stages all 24 trees were grown in buckets with 51 aerated solution. During the treatment one quarter of the plants remained on aerated solution $\left(\mathrm{H}^{+}\right)$, one quarter received aerated tap water $\left(\mathrm{W}^{+}\right)$, the rest was not aerated either on Hoagland solution $\left(\mathrm{H}^{-}\right)$or on tap water $\left(\mathrm{W}^{-}\right)$.

In all treatments the time course of growth was followed by length measurements of the shoots whereas in regular harvests the increase in weight of young growing parts and older tissues of shoots and roots, was determined. In the ovendried material the macronutrient elements $\mathrm{Ca}, \mathrm{Mg}, \mathrm{K}, \mathrm{N}$ and $\mathrm{P}$ were estimated. In addition each sample was analyzed for the soluble carbohydrate content.

In each section of the next chapter the results of the experiments $A, B$, and $C$ are directly compared.

\section{Results}

\section{Growth}

Shoot length of control plants increased in a regular way in all three experiments (Fig. 1). High water-tables $\left(\mathrm{W}_{0}\right)$ and lack of aeration in the nutrient solution $(\mathrm{H}-, \mathrm{W}-)$ resulted in a considerable reduction of shoot growth almost directly from the beginning of the treatment. This reduction increased with time and in the water culture experiment a complete check was obtained. This also happened to be the case when the nutrient solution was replaced by tap water either aerated or not aerated. Dry weight of shoots followed a similar trend (Fig. 2). In contrast the weight of young roots responded differently. Lack of aeration affected root growth in the same way as shoot growth, but aerated tap water which led to a check of shoot growth resulted in an even enhanced root growth.

These results suggest that the rate of shoot growth depended directly on root activity, and the check of shoot growth at aerated tap water, where the roots were thriving very well, may indicate that the absorption of minerals was most likely the determining factor for shoot growth. 

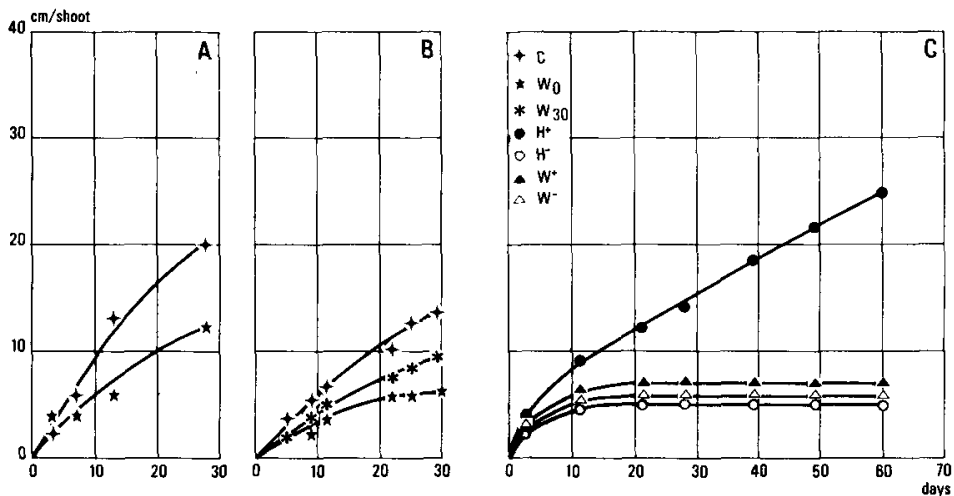

Fig. 1. Growth of top shoots in relation to treatments 1.

A. Pot experiment 1968, clay soil; $\mathrm{C}=$ control; $\mathrm{W}_{0}=$ water-table $0 \mathrm{~cm}$ below surface.

B. Pot experiment 1969 , clay soil; $\mathrm{C}=$ control; $\mathrm{W}_{\mathrm{s0}}=$ water-table $30 \mathrm{~cm}$ below surface; $\mathrm{W}_{0}=$ water-table $0 \mathrm{~cm}$ below surface.

C. Water culture experiment $1969 ; \mathrm{H}+=$ control, aerated nutrient solution; $\mathrm{H}-=$ nutrient solution without aeration; $\mathrm{W}+=$ aerated tap water; $\mathrm{W}-$ tap water without aeration.

1 Time axis in all cases days after beginning of the treatment. Conditions before the treatment similar to the control during the treatment.
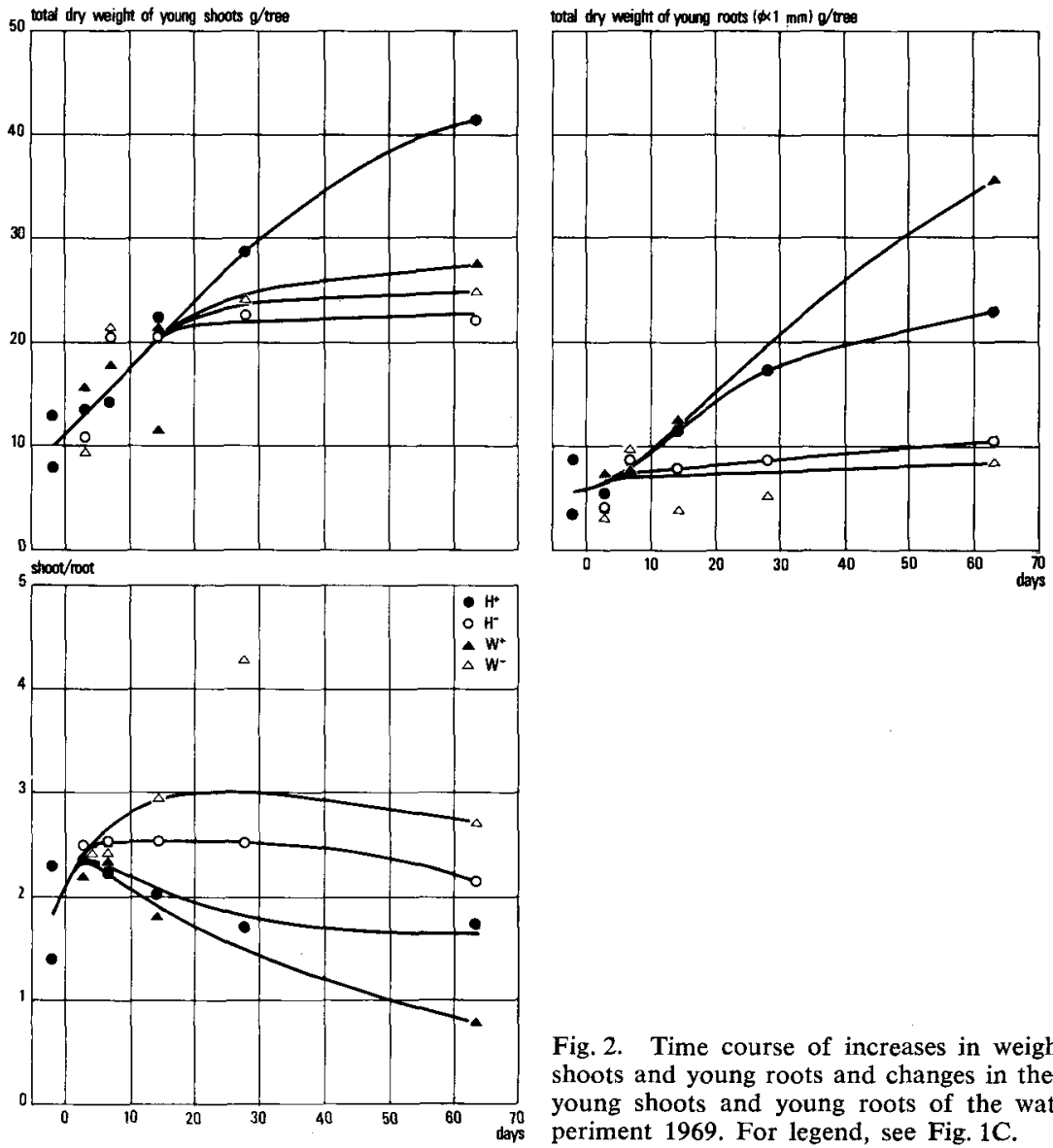

Fig. 2. Time course of increases in weight of young shoots and young roots and changes in the ratio between young shoots and young roots of the water culture experiment 1969. For legend, see Fig. 1C. 
Contrary root growth appeared to be affected primarily by the aeration of the roots. Obviously the requirements for minerals were covered rather well by translocation from older parts of the plants. The rather independent behaviour from the mineral supply in the root environment is a common feature of roots as found in many occasions and discussed at length, among others, by Brouwer (1962, 1963). It also indicates that in apple trees grown in this way shoot growth and root growth are competing for carbohydrates as also suggested by Rogers and Head (1968).

In the soil culture experiments in a part of the soil column root growth of a number of plants was followed by length measurements of roots appearing behind a transparant perspex window. Inundattion resulted in a direct check of root elongation.

Although root elongation stopped immediately after flooding and after withholding the aeration there still was a slow increase in root dry weight in both cases. Obviously some dry matter accumulated in the roots without extension growth. A same phenomenon was formerly observed by Grobbelaar (1963) growing maize plants at low root temperatures.

As a consequence of these growth reactions the ratio between young shoots and young roots was affected by the treatment (Fig. 2).

\section{Mineral contents}

Since all treatments primarily involved changes in the root environment it may be expected that root activity was affected. Although direct absorption measurements were only obtained from the water culture experiment the changes in mineral content of the above-ground plant parts are assumed to be a fair reflection of absorptive properties. Data of the contents of $\mathrm{Ca}, \mathrm{K}, \mathrm{Mg}, \mathrm{N}$ an $\mathrm{P}$ are available, but only those of $\mathrm{Ca}, \mathrm{K}$ and $\mathrm{N}$ are presented. As will be shown $\mathrm{Ca}$ and $\mathrm{K}$ reacted in a rather different way whereas the nitrogen content appeared to be controversially related with the soluble sugar content.

In Fig. 3 the effect of the various treatments on the calcium content of young and old leaves and of young roots is plotted against time after beginning of the treatments. Reduction of the oxygen supply resulted in all cases in a direct reduction in the calcium content of both types of leaves. The decrease in calcium content was particularly clear during the first 10 or 15 days, i.e. during the period that there was still some shoot growth. The effect of lack of aeration on leaf calcium content was evident in all cases when the time course for each treatment is considered but was still more pronounced when the contents of the treated plants are compared with those of the control plants.

The calcium contents of the roots behaved differently. In soil culture the content in the $W_{0}$-treatment tended to be higher than that of the control throughout the whole period, probably due to adsorptive binding on the root tissue, whereas in water culture the root calcium content in tap water was much lower than in nutrient solution. It is remarkable that on aerated tap water with rather well growing roots the root calcium content decreased in the same way as in not aerated tap water, whereas the leaf calcium content tended to increase somewhat. The calcium content of the tap water (27 $\mu \mathrm{eq} / \mathrm{l})$ might be responsible for this picture indicating that much of the calcium absorbed from tap water was transported to the shoots, whereas in the roots it was diluted by the abundant growth.

The figures indicate that the calcium content of younger leaves was much lower than that of older leaves. Further on the continuous supply as available in nutrient solution induced a gradually increasing content during the course of the experiment which coincided with a decreasing overall growth rate of the shoots. The direct response 

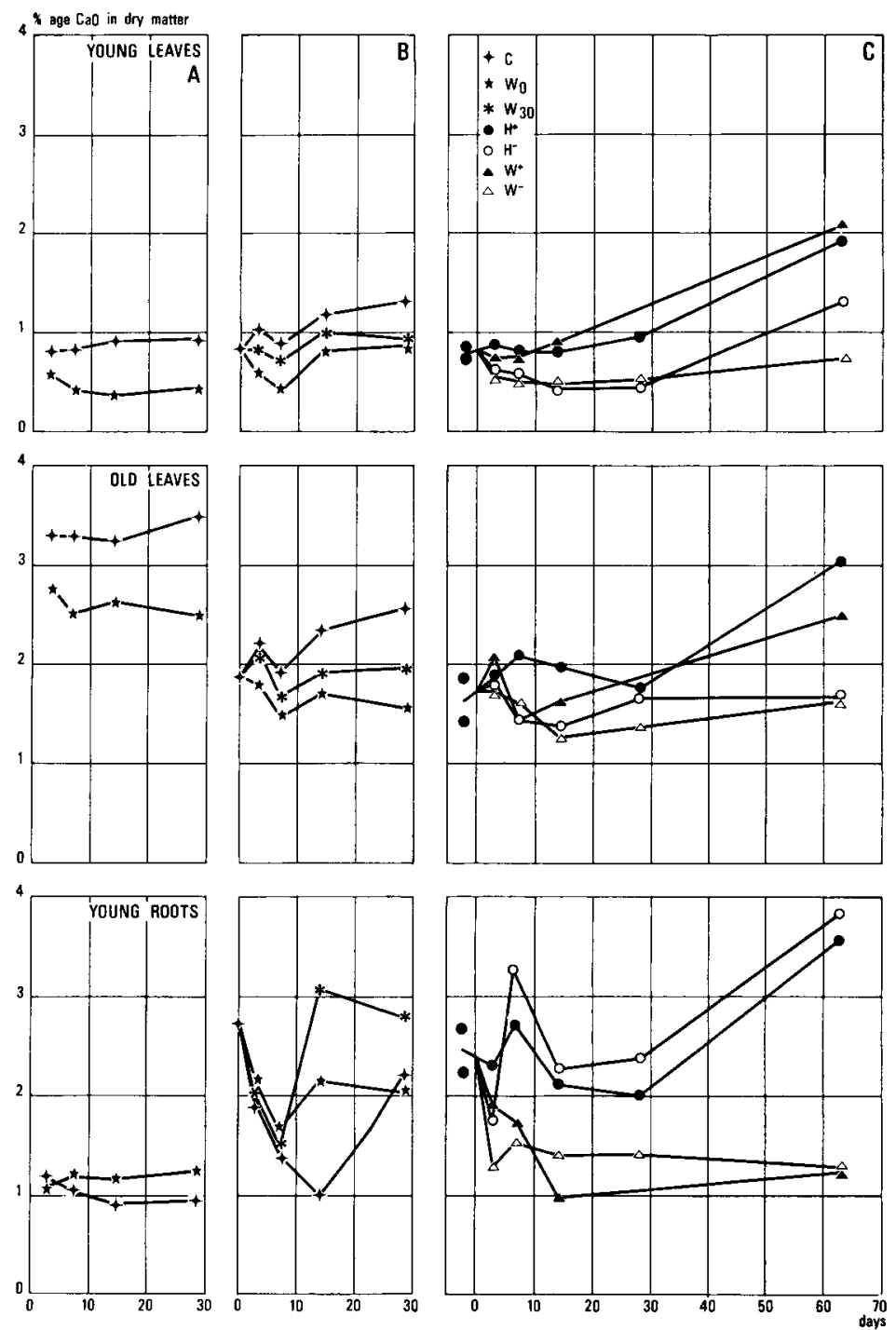

Fig. 3. Changes in calcium content of young leaves (top), old leaves (middle) and young roots (bottom) after starting the treatments (time 0). For legend, see Fig. 1A, B and C.

of the calcium content on withholding aeration suggests a directly reduced absorption rate combined by a somewhat less reduced growth rate of the leaves.

Fig. 4 shows the effect of partial inundation. A flooding of only 1 day a week already induced a lower leaf calcium content which effect gradually increased up to inundation periods of 4 days a week. Longer inundation treatments did not exceed this maximal effect. Hence it may be concluded that normal water-tables maintained only for 0 to 3 days a week were too short for even partial recovery of the root system. 

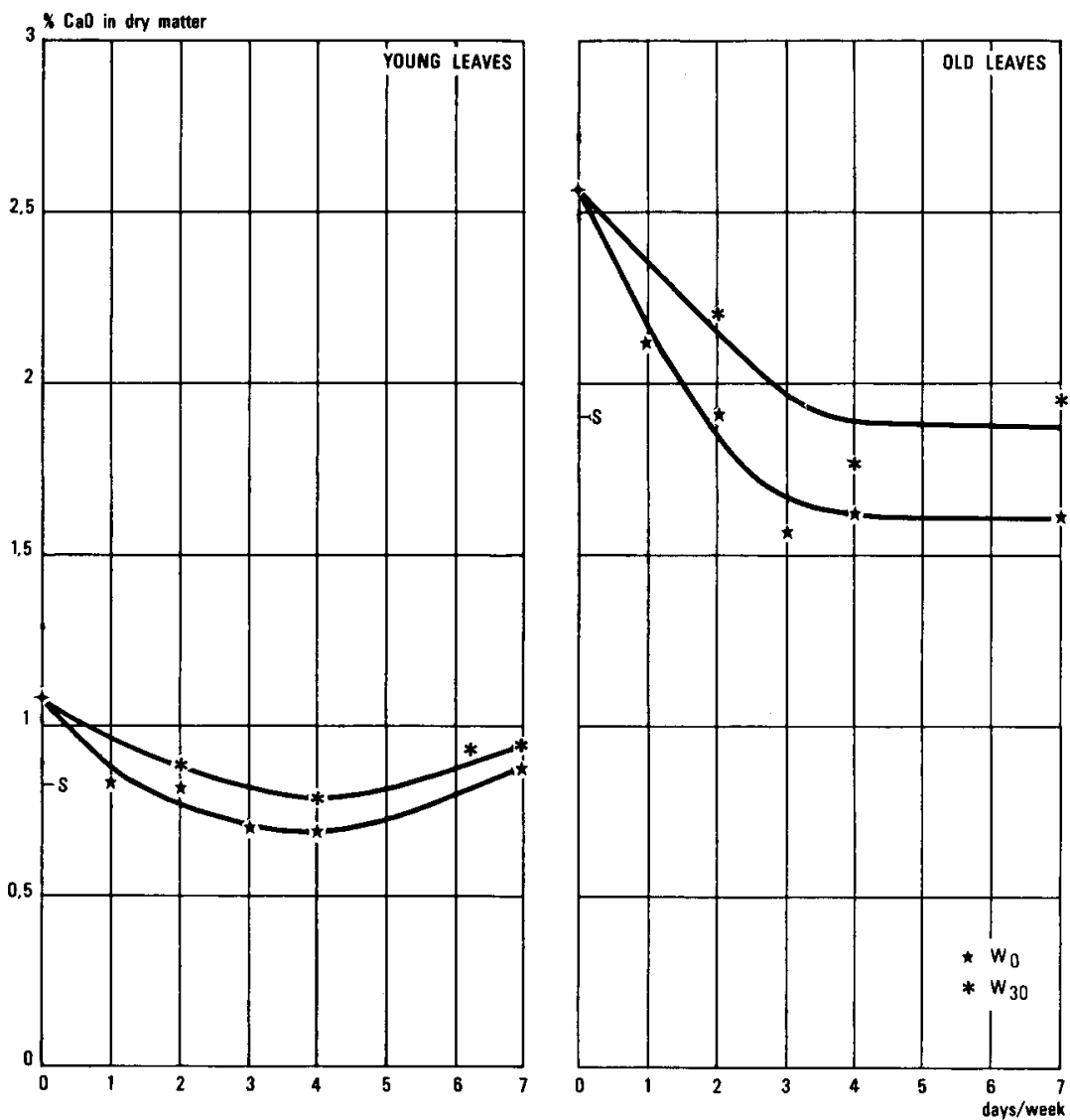

Fig. 4. Calcium content at $23 / 7 / 69$ in old and young leaves of apple trees grown in pots with clay soil and water-table kept at $0 \mathrm{~cm}$ below surface $\left(W_{0}\right)$ or $30 \mathrm{~cm}$ below surface $\left(W_{30}\right)$ for 0 to 7 days every week from $22 / 6 / 69$ to final harvest at $23 / 7 / 69$ (s = starting level at $22 / 6 / 69$ ).

The potassium contents in the various tissues are plotted in Fig. 5 and 6. Although the general picture was more or less the same as for the calcium content there were pronounced differences in details. In the first place the differences in potassium content between young leaves and older leaves of the control plants were negligible. The induced reduction was most pronounced in the older leaves and continued throughout the experimental period. With respect to potassium the effects in nutrient solution culture and soil culture were identical. Clearly lack of aeration stopped potassium absorption almost completely. In solution culture the curves for tap water, both aerated and not aerated, coincided completely with Hoagland solution minus aeration for the first 15 to 30 days. Thereafter minor differences occurred since in the tap water more potassium leached out of the plants than in Hoagland solution. This proces might have been responsible also for the differences between potassium and calcium in the experiment with alternating inundation. Here the effect on potassium content appeared to increase up to 7 days a week whereas that on calcium content already reached a maximum at 4 days a week. 

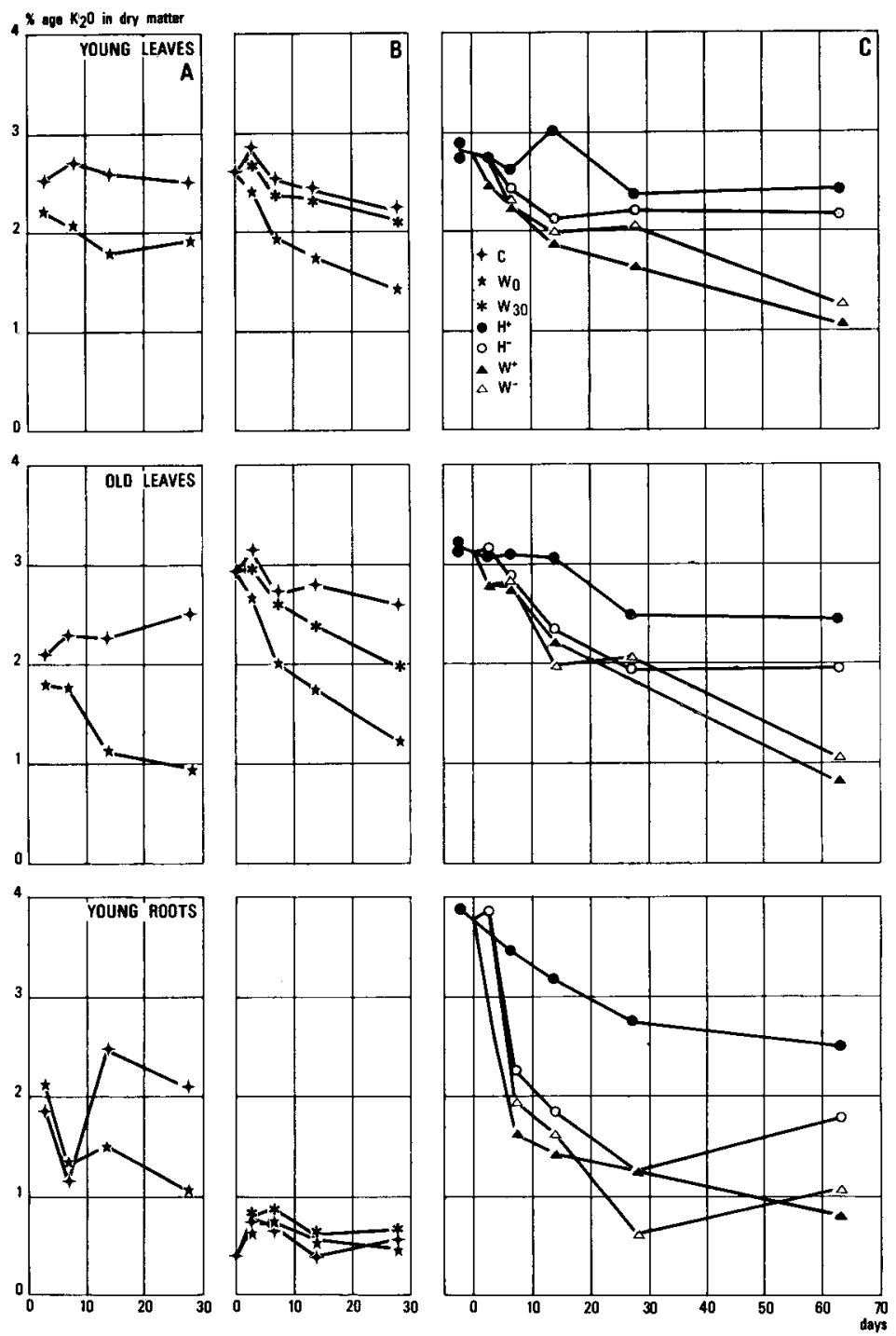

Fig. 5. Changes in potassium content of young leaves (top), old leaves (middle) and young roots (bottom) after starting the treatments. For legend, see Fig. 1A, B and C.

The overall picture indicates that the absorption of both calcium and potassium immediately stopped by lack of aeration, but that especially in the younger leaves the effect on calcium content was more serious since a readier redistribution of potassium occurred from older tissues.

In Fig. 7 and 8 the nitrogen contents are given. The general trend is comparable with that of potassium. The decrease in time as found in the control plants was slightly 

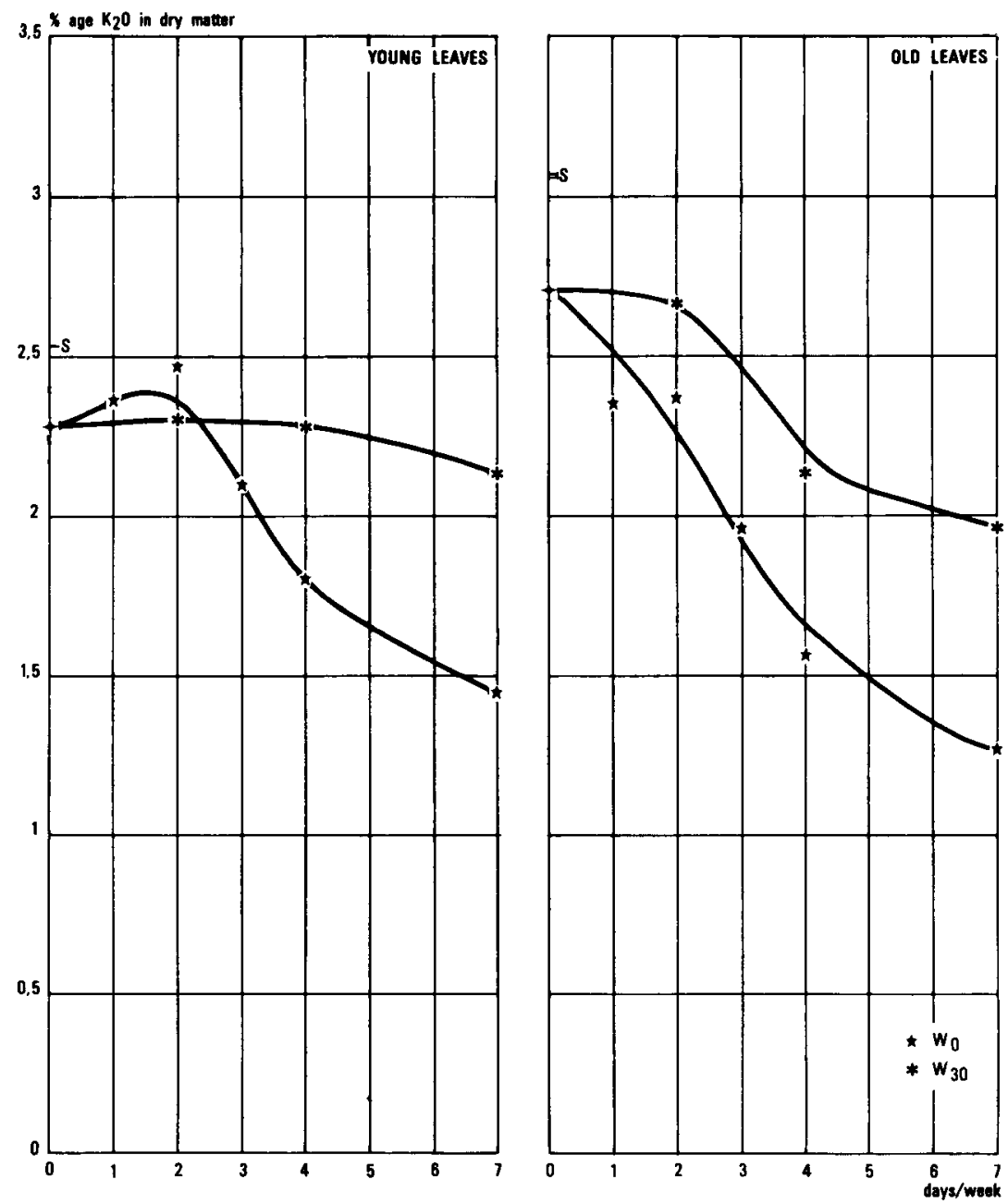

Fig. 6. Potassium content in old and young leaves of apple trees grown in pots with clay soil and groundwater table kept at $0 \mathrm{~cm}$ below surface $\left(\mathrm{W}_{0}\right)$ or $30 \mathrm{~cm}$ below surface $\left(\mathrm{W}_{\mathrm{a}}\right)$ for 0 to 7 days every week from $22 / 6 / 69$ to final harvest at $23 / 7 / 69$ ( $\mathrm{s}=$ starting level).

more pronounced. Since this also occurred in the plants on water culture ageing was assumed to be involved. Lack of aeration induced a difference in nitrogen content between control plants and treated plants that was comparable with the differences in potassium content. This indicates that nitrogen was redistributed as readily as potassium.

\section{Soluble carbohydrate content}

The soluble sugar content of plants is known to vary considerably both during the course of the day and during development. Superimposed treatments are also found 

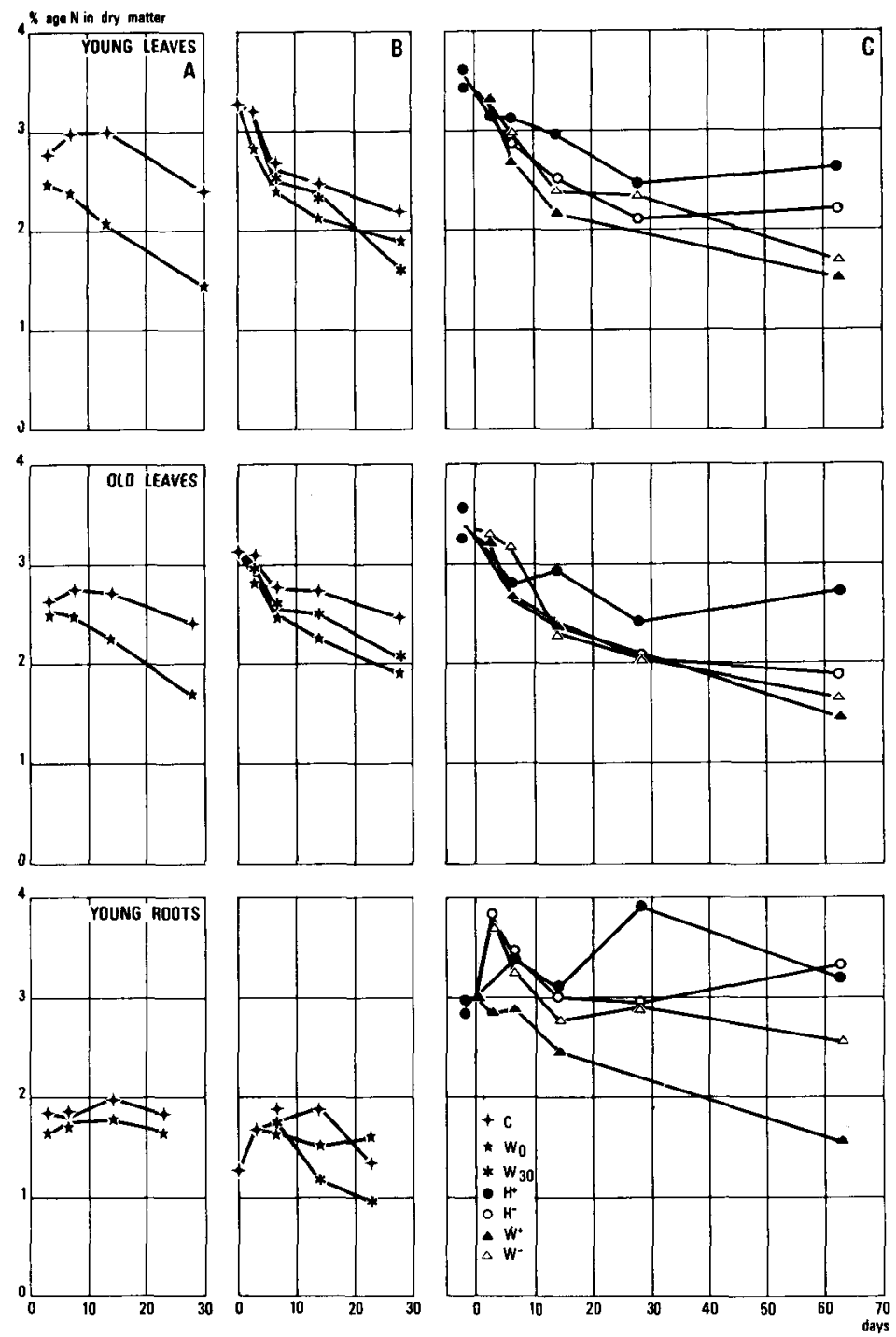

Fig. 7. Changes in total-nitrogen content of young leaves (top), old leaves (middle) and young roots (bottom) after starting the treatments. For legend, see Fig. 1A, B and C.

to influence dry matter content and soluble sugar content. Among others Alberda (1965) observed in perennial rye grass increased soluble carbohydrate contents with decreasing nitrogen supply. Grobbelaar (1963), growing maize plants on nutrient solutions of varying temperatures $\left(5^{\circ}\right.$ to $\left.40^{\circ} \mathrm{C}\right)$, found high values of both dry matter content and soluble sugar content in shoots and roots at suboptimal and supra optimal root temperatures. Brouwer (1962) described the same for various species. These examples are all fitting 

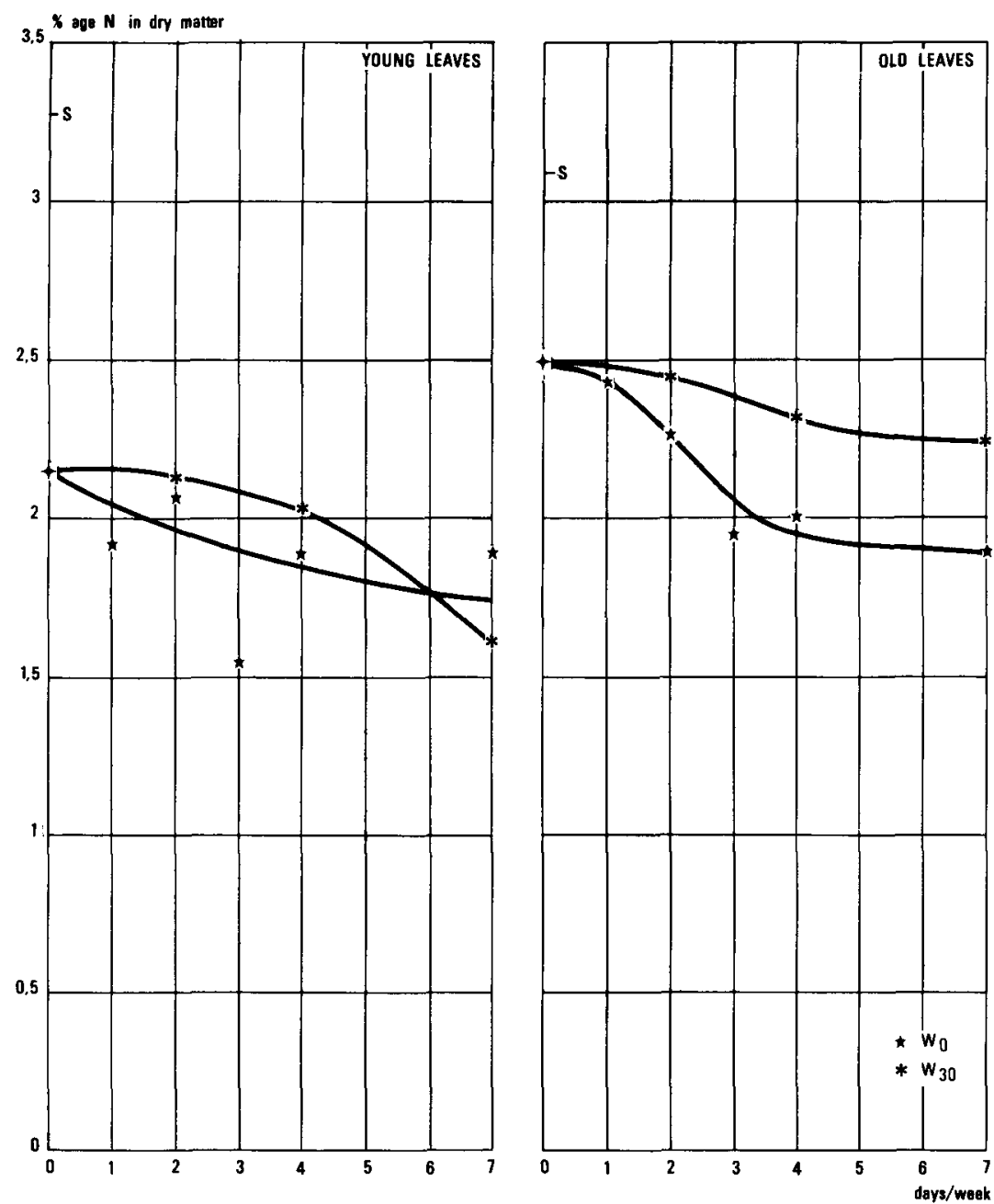

Fig. 8. Total nitrogen content in old and young leaves of apple trees grown in pots with clay soil with groundwater table kept at $0 \mathrm{~cm}$ below surface $\left(\mathrm{W}_{0}\right)$ or $30 \mathrm{~cm}$ below surface (W $\left.\mathrm{W}_{30}\right)$ for 0 to 7 days a week from $22 / 6 / 69$ to final harvest at $23 / 7 / 69$ ( $\mathrm{s}=$ starting level).

very well with the well-known phenomenon that a reduction in growth rate leads very of ten to an increased dry matter content, since growth rate is more sensitive to various unfavourable conditions than the rate of photosynthesis. Hence the products of photosynthesis are not converted into structural material and tend to accumulate as reserves in the form of starch and sugars.

The results of the present experiments are in agreement with this general concept. Where growth was reduced the sugar content rose above that of the controls. This was more in particular the case in the 1969 experiments both in soil and water culture 

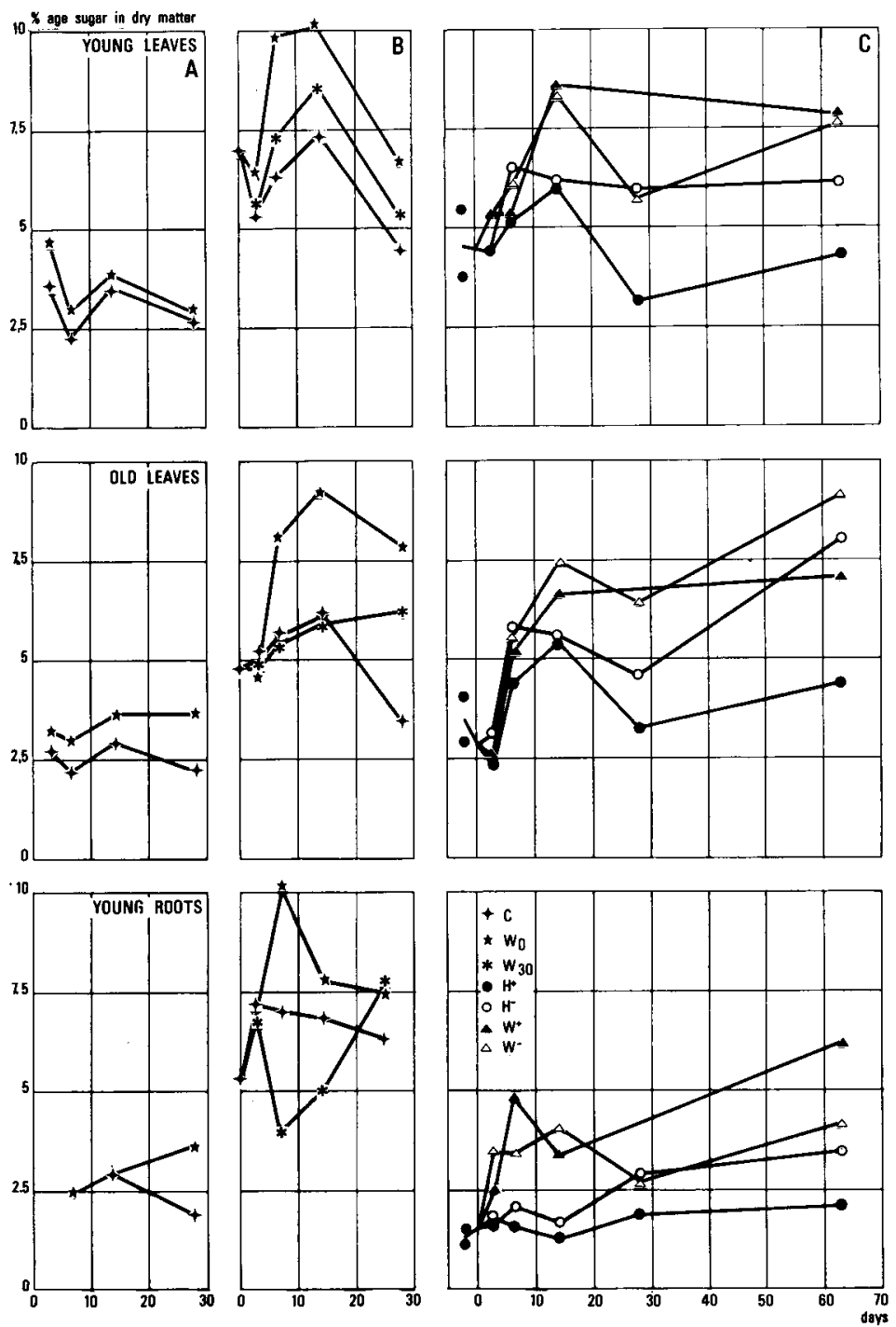

Fig. 9. Changes in soluble sugar content (in glucose equivalents) of young leaves (top), old leaves (middle) and young roots (bottom) after starting the treatments. For legend, see Fig. 1A, B and C.

(Fig. 9 and 10). In 1968 the differences in soluble sugar content were much smaller, but in the same direction. This may be due to the less clear weather we had in that year.

Comparing the nitrogen contents (Fig. 7 and 8) with the soluble sugar contents (Fig. 9 and 10) shows that in all cases nitrogen contents and sugar contents reacted in opposite directions. 

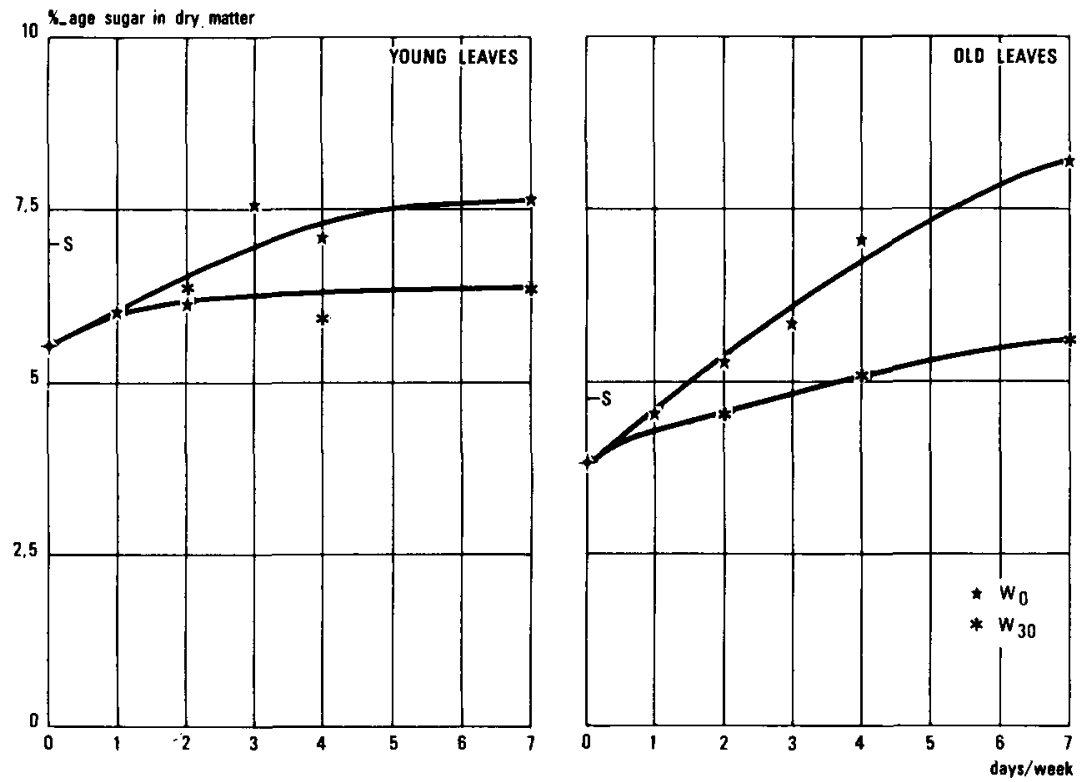

Fig. 10. Soluble sugar content in old and young leaves of apple trees grown in pots with clay soil with groundwater table kept at $0 \mathrm{~cm}$ below surface $\left(W_{0}\right)$ or $30 \mathrm{~cm}$ below surface $\left(W_{30}\right)$ for 0 to 7 days every week from $22 / 6 / 69$ to final harvest at $23 / 7 / 69$ (s = starting level).

\section{Discussion}

In practice it is general experience that acid soils and/or low availability of calcium (van Schreven and van der Boon, 1962) as well as a high $\mathrm{K} / \mathrm{Ca}$ ratio or a high leaf/ fruit ratio (Wiersum, 1966) or an excess of nitrogen (Yamazaki and Mori, 1961) all lead to an increased occurrence of bitter pit in apple fruits. Van Segeren and Visser (1969) showed that bad aeration conditions in the soil led to the same phenomenon. This points among others to the importance of soil physical conditions in preventing this type of diseases. Although in the literature on mineral absorption sometimes calcium uptake has been considered to be less influenced by metabolism than, for instance, potatssium uptake (Brouwer, 1965) the present experiments clearly show that withholding aeration affected the uptake of all minerals to the same degree. This was confirmed in experiments in 1970 (to be published elsewhere) in more direct absorption measurements in greenhouse and climate rooms. The data presented above indicate that the special role of calcium is not due to its properties with respect to the absorption process but to the fact that calcium is less readily redistributed (cf. Wiersum, 1966).

Although we have been using 'Golden Delicious' the shifts in mineral and sugar contents in the various types of plant tissue very much resemble the shifts reported by Visser (1968) in the leaves of the 'Cox' variety following the incidence of a very special type of leaf shedding, called 'Cox disease'. In fact these experiments showed that comparable changes in mineral contents could easily be induced artificially. Continuation of the water culture experiments, now using the variety 'Cox Orange', resulted in comparable changes in mineral content. And in some cases the natural disease phenomena were found. The experiments are to be continued to get better informed in this respect. 


\section{References}

Alberda, Th., 1965. The influence of temperature, light intensity and nitrate concentration on dry* matter production and chemical composition of Lolium perenne L. Neth. J. agric. Sci. 13: $335-360$.

Brouwer, R., 1962. Distribution of dry matter in the plant. Neth. J. agric. Sci. 10: 361-376.

Brouwer, R., 1963. Some physiological aspects of the influence of growth factors in the root medium on growth and dry-matter production. Jaarb. Inst. biol. scheik. Onderz. LandbGew. 1963: 11-30.

Brouwer, R., 1965. Root growth of grasses and cereals. In: Root growth. Proc. 12th Easter School agric. Sci. Univ. Nottingham, p. 153-166.

Butyn, J., 1961. Bodembehandeling in de fruitteelt. Thesis, Wageningen.

Grobbelaar, W., 1963. Responses of young maize plants to root temperatures. Meded. LandbHogesch. 63: 1-71.

Kloes, L. J. van der, 1965. Bodemkundige aspecten van de teelt van enige tuinbouwgewassen. Thesis, Wageningen.

Mori, H., 1966. Technique for growing deciduous fruit trees in waterculture. Proc. Am. Soc. hort. Sci. 88: 253-261.

Oud, P., 1968. Nieuwe inzichten betreffende de Cox's ziekte. Fruitteelt 58: 1172-1174.

Rogers, W. S. \& G. C. Head, 1968. Factors affecting the distribution and growth of roots of perennial woody species. In: Root growth. Proc. 15th Easter School agric. Sci. Univ. Nottingham, p. 280-295.

Schreven, W. A. \& J. van der Boon, 1962. Stip in appels. Meded. Dir. Tuinb. 25: 87-92; 181-191.

Segeren, W. A. \& J. Visser, 1969. Het waterstandenproefveld in de IJsselmeerpolders. Tuinbouwmededelingen 32: 180-197.

Visser, J., 1968. De invloed van het bodemmilieu op het voorkomen van Cox's ziekte in de IJsselmeerpolders. Flevoberichten (Zwolle) 56.

Wiersum, L. K., 1966. Calcium content of fruits and storage tissues in relation to the mode of water supply. Acta bot. neerl. 15: 406-418.

Yamazaki, T. \& H. Mori, 1961. Studies on bitterpit in relation to mineral nutrition. J. Jap. Soc. hort. Sci. $30: 347-350$. 